\title{
Positive Charge-doping on Carbon Nanotube Walls and Anion-directed Tunable Dispersion of the Derivatives
}

\author{
Ueon Sang Shin, ${ }^{\dagger, *, *}$ Jonathan C. Knowles, ${ }^{\dagger, \#}$ and Hae-Won Kim ${ }^{\dagger, \star, \S, *}$ \\ ${ }^{\dagger}$ Department of Nanobiomedical Science \& WCU Research Center, Dankook University, Cheonan 330-714, Korea \\ ${ }^{*}$ E-mail: usshin12@dankook.ac.kr \\ Institute of Tissue Regeneration Engineering (ITREN), Dankook University, Cheonan 330-714, Korea \\ ${ }^{\S}$ Department of Biomaterials Science, School of Dentistry, Dankook University, Cheonan 330-714, Korea \\ *E-mail:kimhw@dku.edu \\ ${ }^{\#}$ Division of Biomaterials and Tissue Engineering, Eastman Dental Institute, University College London, \\ 256 Gray's Inn Road, London, WC1X 8LD, UK \\ Received October 9, 2010, Accepted March 28, 2011
}

\begin{abstract}
An efficient and novel positive charge-doping on the sidewalls of multi-walled carbon nanotubes has been achieved in the presence of tetrahydrofuran as a dopant and Lewis acidic ionic liquids, $[\mathrm{bmim}] \mathrm{Sb}_{\mathrm{n}} \mathrm{F}_{5 \mathrm{n}+1}(\mathrm{n} \geq 2$; bmim = 1-butyl-3-methylimidazolium), as an activator, leaving air-stable derivatives having positively charged sidewalls and the counter anions, $\left[\mathrm{MWCNT}^{\mathrm{y}}\right]\left[\mathrm{SbF}_{6}{ }^{-}\right]_{\mathrm{y}}(\mathrm{MWCNT}=$ multi-walled carbon nanotube). The derivatization took place very fast in one-pot and under mild reaction conditions. The ionic structure enabled a tunable dissolution of the derivatives in various solvents through anion exchange.
\end{abstract}

Key Words : Multi-walled carbon nanotubes, Positive charged sidewalls, Dissolution, Lewis acidic ionic liquids

\section{Introduction}

Due to the valuable properties of carbon nanotubes $(\mathrm{CNTs}),{ }^{1-3}$ there has been a great deal of interest in chemical modification of CNTs to achieve dissolution in various solvents. ${ }^{4-17}$ Of the various techniques employed to dissolve CNTs in a suitable solvent, the oxidative cutting of CNTs using a strong oxidant and acidic medium at high temperatures has been the method of choice, which has served as a very useful tool. ${ }^{4-9}$ Highly reactive chemicals such as alkali metals and Brønsted super acids have also been employed, often leading to charged CNT-derivatives which are quite unstable under ambient conditions. ${ }^{10-13}$ Given the significant damage caused during these harsh processes, the pristine CNTs tend to ultimately lose their primary properties and often become air sensitive. To avoid these serious consequences, polymers ${ }^{14}$ and several types of solubilizers ${ }^{15,16}$ were employed in excess. However, the macromolecular behaviors of solubilizer-CNT complexes, affected by the interactions between adjacent solubilizer-wrapped CNTs, have limited their applications. Consequently, it is highly desirable to develop a new method for the dissolution of CNTs to satisfy the following requirements: simplicity and mildness of the procedure to allow for large scale production; tunable solubility of the derivatives; and maximal maintenance of the morphology and physicochemical properties of the original CNTs. Direct sidewall functionalization is expected to be difficult due to the extremely low reactivity of the sidewalls. ${ }^{17-24}$ However, it has recently been found by the authors that Lewis acidic ionic liquids (ILs) such as $[\mathrm{bmim}] \mathrm{Al}_{2} \mathrm{Cl}_{7}$ or $[\mathrm{bmim}]\left[\mathrm{Sb}_{\mathrm{n}} \mathrm{F}_{5 \mathrm{n}+1}\right](\mathrm{n} \geq 2)(\mathrm{bmim}=$ 1-butyl-3-methylimidazolium) greatly accelerate organic reactions. $^{13,14}[\mathrm{bmim}] \mathrm{Al}_{2} \mathrm{Cl}_{7}$ was effectively used for the hydrogenation of many aromatic compounds not only to activate the conjugated $\mathrm{C}=\mathrm{C}$ bonds via an ionic mechanism, but also to stabilize the ionic intermediates by the cations and anions of ILs. ${ }^{25}$ Moreover, in the case of the catalyst [bmim] $\mathrm{Sb}_{n} \mathrm{~F}_{5 \mathrm{n}+1}(\mathrm{n} \geq 2)$ exhibiting stronger acidity, it was also possible that even the thermodynamically stable ring of tetrahydrofuran (THF) solvent can be easily opened to create strong electrophilic species. ${ }^{26}$ Thus, it is a question put forth by us whether the strong reactivity of the Lewis acidic IL and the stabilization effects of ILs upon the ionic intermediates can allow for direct sidewall functionalization of CNTs through Friedel-Crafts type alkylation.

Herein, for the first time, a novel strategy to fulfill most of the aforementioned requirements is accomplished via alkylation of MWCNTs with Lewis acidic ionic liquid-activated $\mathrm{THF}$ as an electrophilic species, leading to the formation of positively charged sidewalls covalently bonded with butyl alcohol moieties (or their possible oligomers) and a $\mathrm{SbF}_{6}$ counter anion (Fig. 1).

\section{Experimental}

Materials. MWCNTs, purchased from ILJIN Nanotech Co., Ltd. (Seoul, Korea), were synthesized by chemical vapor deposition (CVD). ILs, [bmim]X (X $=\mathrm{SbF}_{6}$, OTf, Cl), were purchased from C-Tri Co., Ltd., Korea (www.c-tri.co.kr), and used without further purification. Their water contents were $<50$ ppm (determined by Karl-Fisher titration). Organic solvents were dried and distilled under an Ar atmosphere 

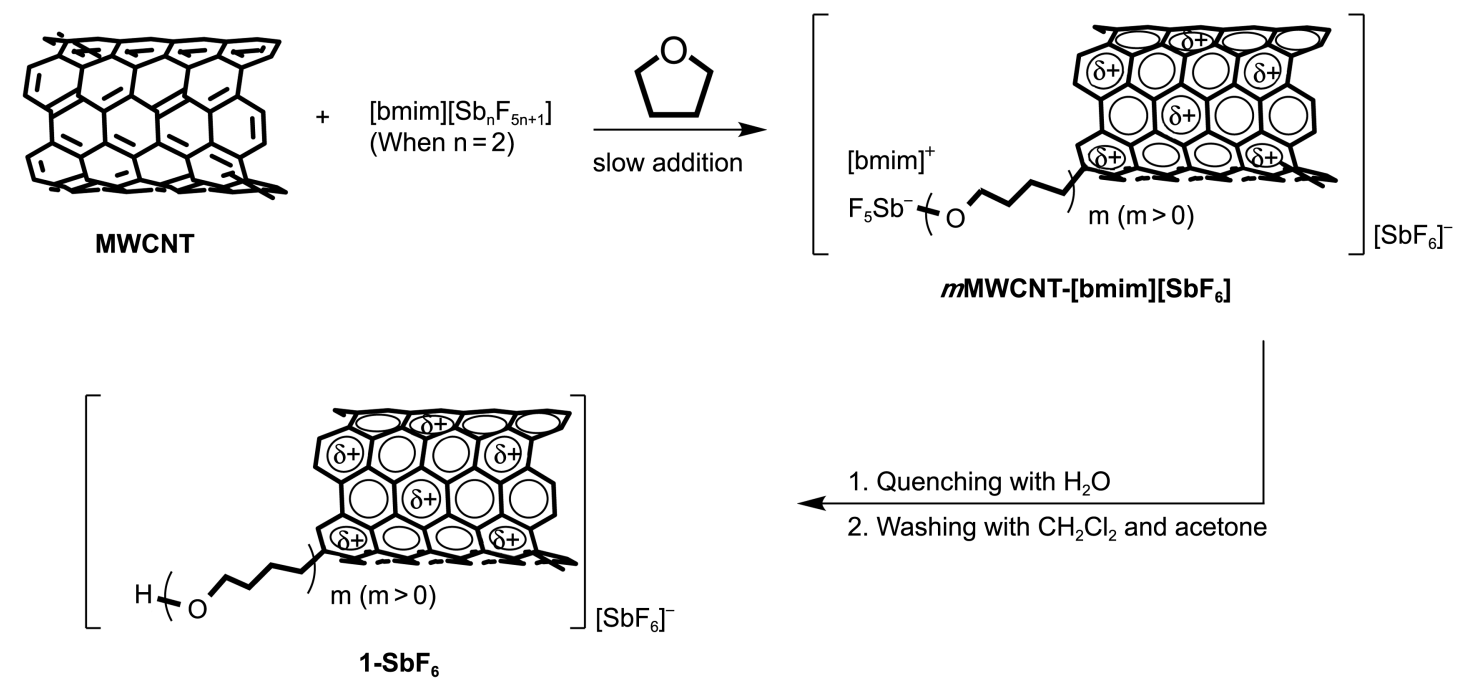

Figure 1. Proposed mechanism for preparation of positively charged $M W C N T$ derivative $\left(\left[\mathrm{MWCNT}^{+\mathrm{y}}\right]\left[\mathrm{SbF}_{6}^{-}\right]_{\mathrm{y}}=\mathbf{1}-\mathrm{SbF}_{6}(\mathrm{y}>0)\right)$.

prior to use. All other chemicals were obtained from commercial sources and used without further purification.

Preparation of $[\mathrm{bmim}]\left[\mathrm{Sb}_{\mathbf{n}} \mathrm{F}_{5 \mathrm{n}+1}\right](\mathrm{n} \geq 2)$ as a Lewis Acidic IL. According to the published procedure, ${ }^{25}$ the Lewis acidic IL was prepared by mixing [bmim] $\left[\mathrm{SbF}_{6}\right]$ and $\mathrm{SbF}_{5}$ in same equivalent under an $\mathrm{Ar}$ atmosphere. $\mathrm{SbF}_{5}$ was transferred to the dried $[\mathrm{bmim}]\left[\mathrm{SbF}_{6}\right]$ under Ar atmosphere over 10 min to afford $[\mathrm{bmim}]\left[\mathrm{Sb}_{\mathrm{n}} \mathrm{F}_{5 \mathrm{n}+1}\right](\mathrm{n} \geq 2)$.

Preparation of Positive Charged MWCNT Bearing $\mathbf{S b F}_{6}^{-}$as a Counteranion, $\mathbf{1 - S b F}_{6}$. Under an Ar atmosphere, [bmim] $\left[\mathrm{Sb}_{2} \mathrm{~F}_{11}\right]$ (when $\left.\mathrm{n}=2\right)(0.16 \mathrm{~g}, 0.28 \mathrm{mmol})$ as a Lewis acidic IL was mixed with a suspension of MWCNTs (200 $\mathrm{mg}, 2.8 \mathrm{mmol}$ based on $\mathrm{C}_{6}$ unit of nanotubes) in $10 \mathrm{~mL}$ of methylene chloride. THF (200 mg, $2.8 \mathrm{mmol}$ ) was slowly added to the suspension, followed by sonication for $15 \mathrm{~min}$. After quenching with $0.1 \mathrm{~mL}$ water, the modified MWCNT powder was filtered through a Teflon membrane and washed with acetone and methylene chloride many times. After drying in a vacuum, the modified MWCNT, 1-SbF 6 , was obtained in yields of $367 \mathrm{mg}$ as an air-stable black powder.

Procedure for Anion Exchange. 1-SbF 6 (30 mg; $10.8 \mathrm{mg}$ (0.05 mmol) $\left.\mathrm{SbF}_{6}{ }^{-}\right)$and $\mathrm{NaCl}(29 \mathrm{mg}, 0.5 \mathrm{mmol})$ were added to a mixture of water $(3 \mathrm{~mL})$ and methanol $(3 \mathrm{~mL})$. The mixture was sonicated for $5 \mathrm{~min}$ and additionally stirred for $3 \mathrm{~h}$ at $25^{\circ} \mathrm{C}$. The resulting MWCNT powder was filtered through a Teflon membrane and washed with water, acetone, and methylene chloride in that order. After drying in a vacuum, the product, 1-Cl, was obtained in a yield of 12.6 $\mathrm{mg}$ as an air-stable black powder.

In the same manner, 1-OTf and 1-tartrate were prepared from $1-\mathrm{SbF}_{6}\left(30 \mathrm{mg} ; 10.8 \mathrm{mg}(0.05 \mathrm{mmol}) \mathrm{SbF}_{6}{ }^{-}\right)$by using [bmim]OTf $(0.14 \mathrm{~g}, 0.5 \mathrm{mmol})$ and potassium sodium tartrate $(0.11 \mathrm{~g}, 0.5 \mathrm{mmol})$ in yields of 17.8 and $17.6 \mathrm{mg}$, respectively.

Extraction of $\mathbf{S b}$ from 1-SbF 6 for Elemental Analysis. 1-SbF 6 (100 mg) was added to a mixture of $\mathrm{H}_{2} \mathrm{SO}_{4}(3 \mathrm{~mL})$ and $\mathrm{HNO}_{3}(3 \mathrm{~mL})$. The mixture was stirred for $48 \mathrm{~h}$ at 120 ${ }^{\circ} \mathrm{C}$. The resulting MWCNT suspension was filtered through a Teflon membrane and the filter cake was washed with a small amount of water. The yellowish filtrate $(7 \mathrm{~mL})$ was subjected to ICP-OES (inductively coupled plasma-optical emission spectrometer) for the quantitative analysis of the $\mathrm{Sb}$ atoms.

Characterization. The elemental analysis was carried out by means of an elemental analyzer using a FLASH EA 1112 (Thermo Elemental, USA) with an error range of $0.1 \%$. The samples were sufficiently dried under a vacuum before the measurement. The quantitative analysis for $\mathrm{Sb}$ was performed by using inductively coupled plasma-optical emission spectrometer (an Iris Intrepid ICP-OES, Thermo Elemental, USA). $2651 \mathrm{ppm}$ of $\mathrm{Sb}$ was found to be present in $7 \mathrm{~mL}$ of the filtrate obtained from $100 \mathrm{mg}$ of $\mathbf{1}-\mathrm{SbF}_{6}$. Matrix-assisted laser desorption/ionization time-of-flight mass spectrometry (MALDI TOF MS; Voyager-DE STR; Negative Polarity) was employed. The modified nanotube-samples were dispersed in THF and mixed with $\alpha$-cyano-4-hydroxycinnamic acid matrix solution. The MALDI-TOF mass spectra correctly showed the corresponding anions with isotopic peaks.

Zeta $(\xi)$ potential measurement was carried out by means of Zetasizer nano ZS90 (Malvern). The FT-Raman spectra of the samples before and after modification were recorded with a Raman spectrometer (Bruker, FRA 106/S) using an Nd-YAG-laser (1064 nm excitation wavelength). The samples were analyzed under dry conditions. The transmission electron microscopy (TEM) images were obtained with a JEM2100F (JEOL, Tokyo, Japan) microscope. The thermogravimetric analysis (TGA) was performed with a Seiko Exstar 6000(TG/DTA6100) (SEIKO INST., JAPAN) at 10 ${ }^{\circ} \mathrm{C} / \mathrm{min}$ under air. The temperature range was from 20 to $1000^{\circ} \mathrm{C}$. The Fourier Transform Infrared Spectrometry (FTIR) was carried out using a PerkinElmer Spectra GX spectrometer (Massachusetts, USA). Homogeneity and dispersion stability analysis of the MWCNT solutions were carried out using a Turbiscane Lab (Leanontech, Korea). X-ray photoelectron spectroscopy (XPS) was conducted using a PHI 5800 ESCA system with a monochromatized aluminum $\mathrm{K}_{\alpha}$ anode (350 W, $25 \mathrm{~mA})$. 

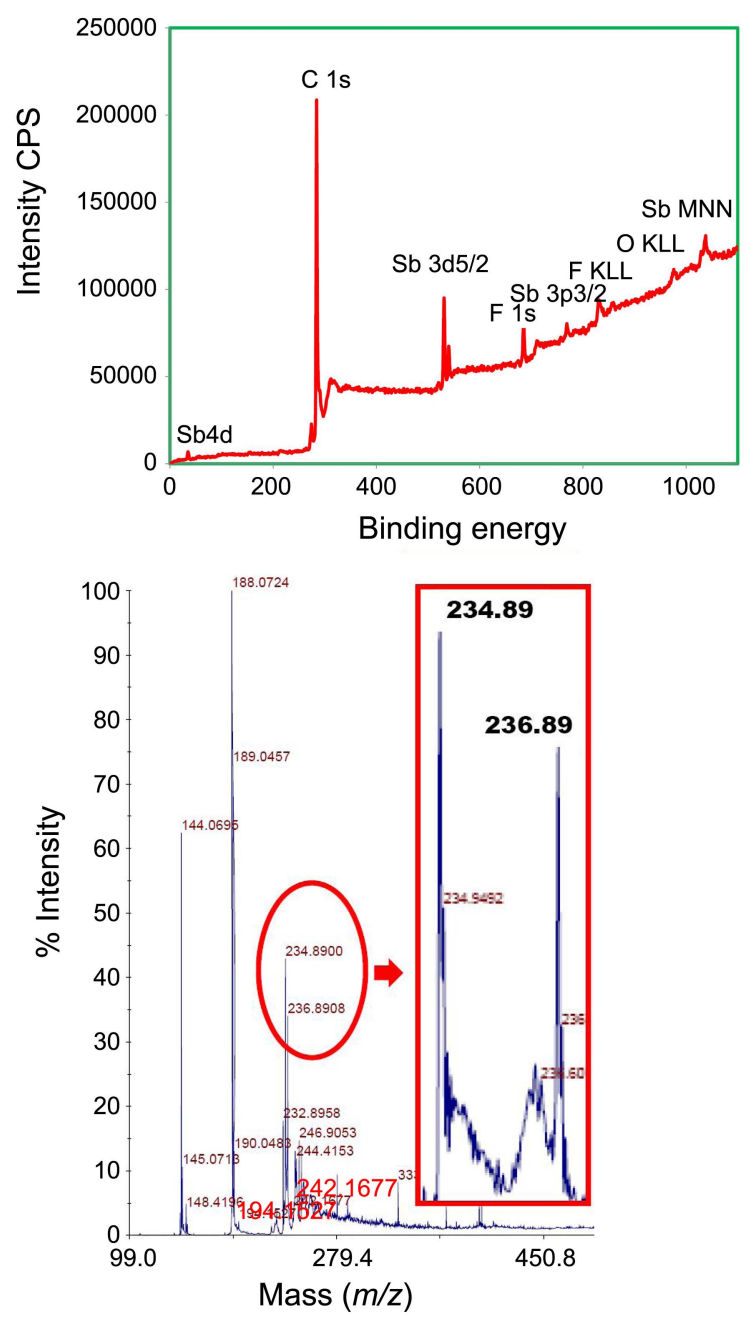

Figure 2. XPS and MALDI-TOF (negative polarity) mass spectra of $1-\mathrm{SbF}_{6}$, top and bottom, respectively.

\section{Results and Discussion}

The covalent and ionic modifications of MWCNTs were performed in an Ar atmosphere with the help of sonication. An inert atmosphere is advisable, in order to minimize the deactivation of the catalyst. During the preparation process as depicted in the proposed mechanism (Fig. 1), the slow adding of THF may lead to rapid converting every THF molecule into highly electrophilic species (THF-SbF 5 complex), minimizing the possible self-oligomerization of THF and maximizing the possible electrophilic reaction of THF$\mathrm{SbF}_{5}$ complex with $\mathrm{C}=\mathrm{C}$ double bonds of MWCNT-sidewalls. In the $15 \mathrm{~min}$ process, positive charges could be developed on MWCNT sidewalls by breaking $\mathrm{C}=\mathrm{C}$ double bonds and delocalized into the highly conjugated double bond system.

The ionic structure of $\mathbf{1}_{-\mathrm{SbF}_{6}}$ was initially determined by several spectroscopic analyses (Fig. 2). In the XPS spectra of $1-\mathrm{SbF}_{6}$, the $\mathrm{SbF}_{6}$ anion-related peaks were clearly observed (35 (Sb 4d), 531 (Sb 3d5/2), and 769 (Sb 3p3/2) in eV; 685 (F 1s) in eV). Moreover, MALDI-TOF (negative polarity) mass spectra very clearly showed not only strong matrix $(\alpha-$ cyano-4-hydroxycinnamic acid)-related peaks, but also
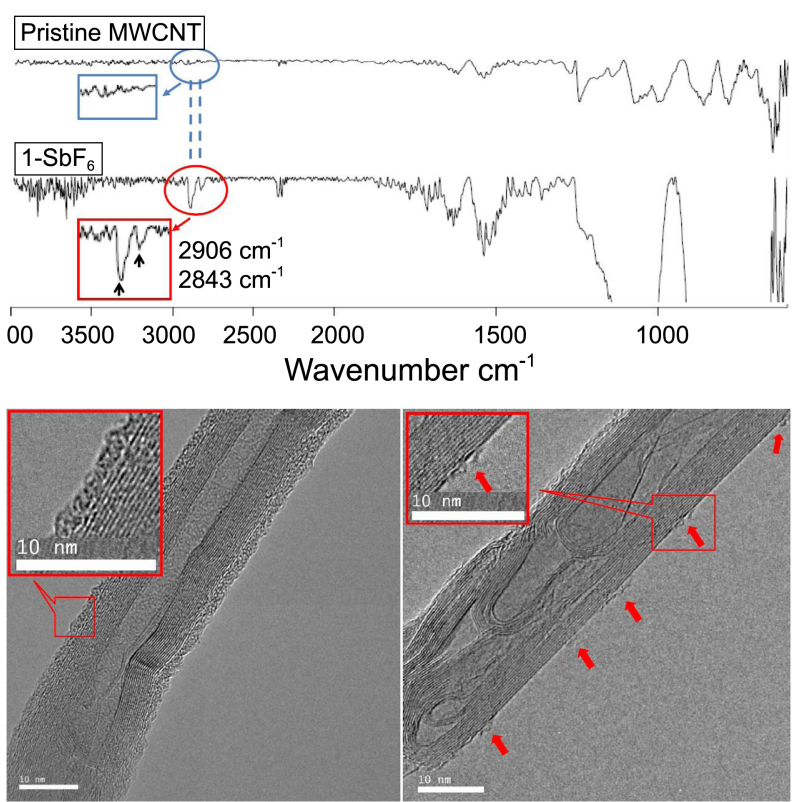

Figure 3. FT-IR spectra (top) and HRTEM images (bottom) of pristine MWCNT (left) and $\mathbf{1}-\mathrm{SbF}_{6}$ (right).

peaks of the anionic species, $\mathrm{SbF}_{6}^{-}$(m/e: 234 (100\%) and $236(74.3 \%))$, strongly supporting the presence of the $\mathrm{SbF}_{6}$ anion part and, at the same time, the ionic structure of 1$\mathrm{SbF}_{6}$. The spectroscopic data including XPS and MALDI TOF agree with the result of elemental analysis as well, in which the final product $\left(1-\mathrm{SbF}_{6}\right)$ contain $\mathrm{SbF}_{6}$ in $36 \mathrm{wt} \%$.

Next, in order to confirm the presence of the butyl alcohol moieties (or their possible oligomers) covalently bonded to the carbon atoms on the sidewalls, FT-IR spectroscopy and HRTEM was employed. The FT-IR spectra show the typical $\mathrm{sp}^{3}$-hybridized C-H stretching bands at 2906 and $2843 \mathrm{~cm}^{-1}$ for the symmetric and asymmetric stretching modes of methylene groups, -( $\left(\mathrm{CH}_{2}\right)-$, (Fig. 3). HRTEM characterization of $1-\mathrm{SbF}_{6}$ gave more direct proof of the presence of butyl alcohol moieties as their possible oligomers. The HRTEM images of $1-\mathrm{SbF}_{6}$ show very clearly not only the presence of these moieties on the outside wall, but also the disappearance of the outer amorphous-carbon phase of pristine MWCNT after modification (see the insets of Fig. 3).

With all spectroscopic evidence of the ionic structure of the derivative $\mathbf{1}-\mathrm{SbF}_{6}$, attention was turned to the dispersion of the modified nanotubes. Positive charges on sidewalls of 1-SbF 6 may effectively accelerate individual dispersion through electric repulsion between the charged nanotubes. However, the solution of $1-\mathrm{SbF}_{6}$ in THF was metastable. To improve the dispersion of the modified nanotubes, the simple anion exchange of $1-\mathrm{SbF}_{6}$ with various anions, $(\mathrm{Cl}$, OTf, tartrate) enabled tunable dissolution (Fig. 4) was performed.

Derivatives 1-Cl and 1-OTf showed the solubility of up to $0.5 \mathrm{mg} / \mathrm{mL}$ in THF. More dramatic tuning of the dispersion ability was achieved by anion-exchange with the tartrate ion. In sharp contrast to $1-\mathrm{SbF}_{6}$ and $\mathbf{1 - C l}$ which agglomerated and floated on water, 1-tartrate was highly hydrophilic and thus could be smoothly dispersed in polar protic solvents 


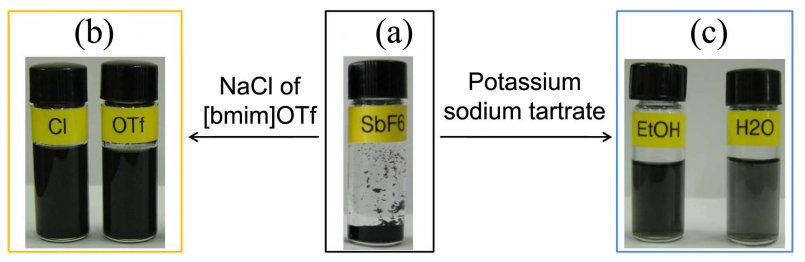

Figure 4. Photographs showing the tuneable dissolution of the modified MWCNTs according to anion type: (a) $\mathbf{1}-\mathrm{SbF}_{6}$ in THF, (b) 1-Cl and 1-OTf in THF, and (c) 1-tartrate in EtOH and $\mathrm{H}_{2} \mathrm{O}$.
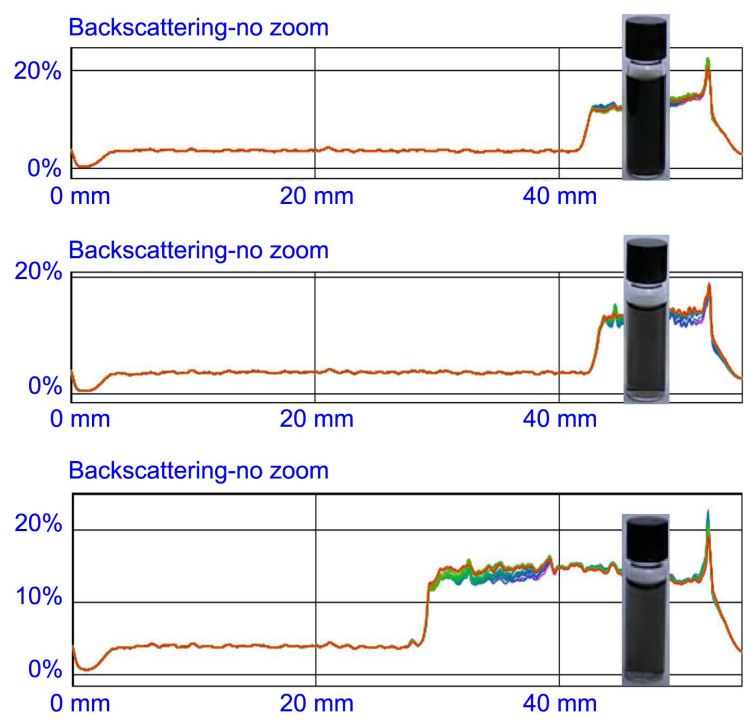

Figure 5. Homogeneity and dispersion stability of (a) $1-\mathrm{Cl} / \mathrm{THF}$, (b) 1-tartrate/EtOH and (c) 1-tartrate $/ \mathrm{H}_{2} \mathrm{O}$.

such as water and ethanol. The anionic species of the derivatives obtained after anion exchange were also detected by MALDI TOF mass spectroscopy (negative polarity), for example, $\mathrm{Cl}^{-}$(m/e: $34.97(100 \%), 36.97$ (32.0\%)), OTf (m/e: 148.95 (100\%), 150.95 (4.5\%), $149.96(1.2 \%))$ and tartrate $^{2-}$ (m/e: 148.00 (100\%), 149.00 (4.3\%), $\left.150.01(1.3 \%)\right)$.

The homogeneity and stability of the nanotube solutions, such as 1-Cl/THF, 1-tartrate/EtOH and 1-tartrate $/ \mathrm{H}_{2} \mathrm{O}$, were confirmed by measuring the backscattered light of a pulsed near infrared light source at $880 \mathrm{~nm}$ (Fig. 5). Solution samples with a height of 28-42 $\mathrm{mm}$ were scanned lengthwise every minute for 30 minutes at $30{ }^{\circ} \mathrm{C}$. During the scanning experiment, there were no noticeable changes in the light flux backscattered by the sample solution, supporting the homogeneity and stability of the modified MWCNT solutions. In addition, the solutions including 1-Cl/THF and 1-OTf/THF maintained their homogeneity even after being left to stand for several months.

Zeta $(\xi)$ potential measurement was used to assess the surface charge of MWCNT derivatives. Conventionally values of $<-30 \mathrm{mV}$ and $>+30 \mathrm{mV}$ would both be considered as high Zeta $(\xi)$ potentials. The Zeta $(\xi)$ potentials of ethanol solutions containing pristine MWCNTs and the derivatives such as $\mathbf{1}-\mathrm{SbF}_{6}, \mathbf{1}-\mathrm{Cl}$ and $\mathbf{1}$-tartrate were recorded at room temperature. Interestingly the hydrophilic derivative 1-tartrate gave a high Zeta $(\xi)$ potential of $-52.6 \mathrm{mV}$, while

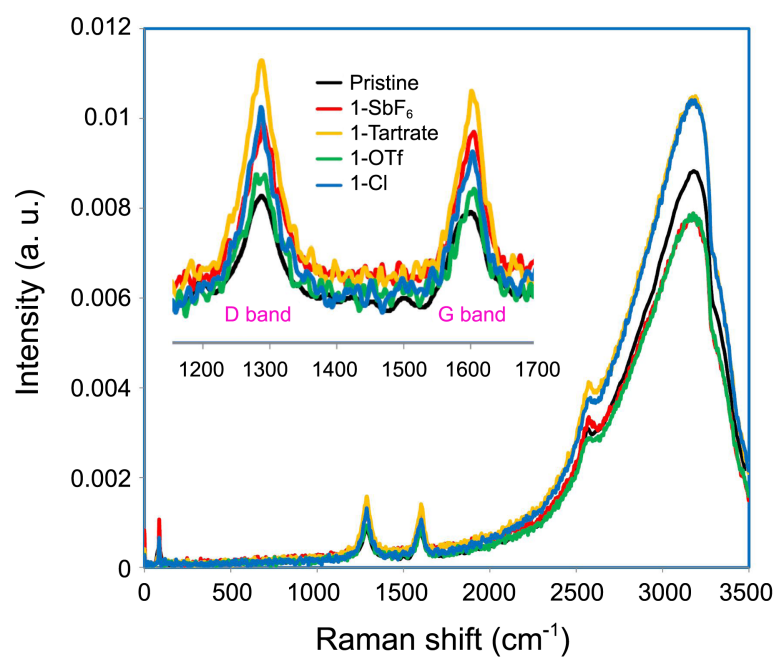

Figure 6. FT-Raman spectra of MWCNTs before and after anion exchange: pristine MWCNT; 1-OTf; $1-\mathrm{SbF}_{6} ; \mathbf{1}-\mathrm{Cl}$; 1 -tartrate.

Table 1. Effect of anions on the D/G ratio and Raman shift

\begin{tabular}{lccccc}
\hline MWCNT & Pristine & 1-SbF $_{6}$ & 1-Tartrate & 1-OTf & 1-Cl \\
\hline D/G ratio & 1.01 & 1.35 & 1.37 & 1.57 & 1.88 \\
Raman Shift & D: 1287 & 1290 & 1287 & 1292 & 1287 \\
$\left(\mathrm{~cm}^{-1}\right)$ & G: 1599 & 1604 & 1601 & 1605 & 1602 \\
\hline
\end{tabular}

pristine MWCNT showed a low Zeta $(\xi)$ potential of -29.7 $\mathrm{mV}$. Others such as $\mathbf{1}-\mathrm{SbF}_{6}$ and $\mathbf{1 - C l}$ showed only moderate increments of Zeta $(\xi)$ potential, for example, -30.2 and $-34.0 \mathrm{mV}$, respectively. These changes according to the type of anion coincide with the dispersibility order of the derivatives in ethanol.

Next, attention was focused on the change in the area ratios and Raman shifts of the D and $G$ bands of the Raman spectra before and after anion exchange, since these changes may be correlated with interactions between positively charged sidewalls of the CNTs and anion species. In fact, the ratios of the $\mathrm{D} / \mathrm{Z}$ bands increased from 1.01 for pristine

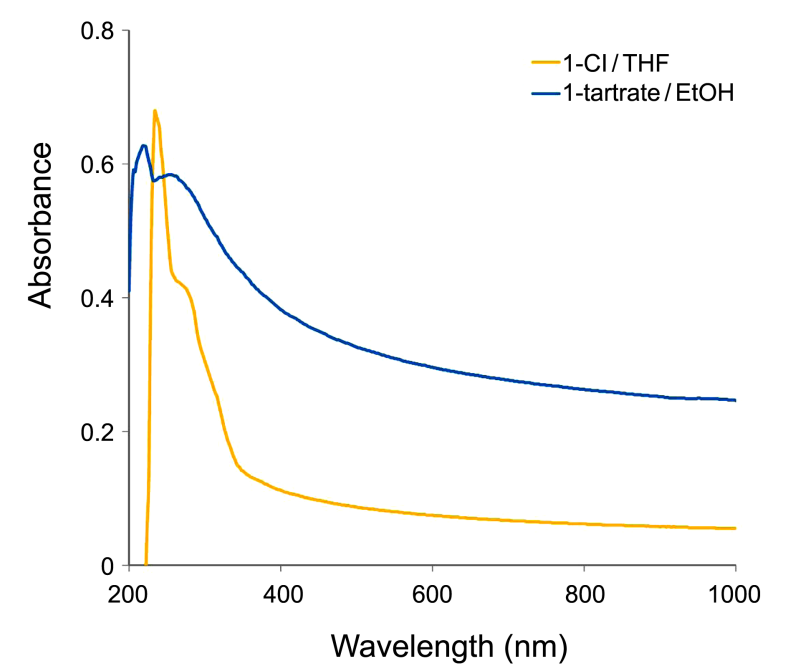

Figure 7. UV-vis-NIR absorption spectra of 1-Cl in THF and 1tartrate in $\mathrm{EtOH}$. 
MWCNTs, up to 1.88 for $\mathbf{1}-\mathrm{Cl}$, depending on the coordinating ability of the anions (Fig. 6, Table 1). Moreover, when the anion of $1-\mathrm{SbF}_{6}$ was exchanged with anions such as tartrate and chloride, the $\mathrm{D}$ and $\mathrm{G}$ bands returned slightly to the values of the pristine MWCNTs. Conversely, the Raman shifts of the MWCNT derivatives bearing weakly coordinating anions such as $\mathrm{OTf}^{-}$and $\mathrm{SbF}_{6}{ }^{-}$were similar.

The UV-vis-NIR absorption spectra clearly evidenced the dissolved state of the MWCNT derivatives 1-Cl and 1tatrate. The UV spectrum (Fig. 7) of 1-Cl in THF exhibits a primary absorption band at $234 \mathrm{~nm}$ and a secondary band at $270 \mathrm{~nm}$, which can be typically observed in the spectra of polynuclear aromatic hydrocarbons. The spectrum of 1tartrate in ethanol showed the primary and secondary absorption bands at 220 and $254 \mathrm{~nm}$, respectively. In such polar solvents, hydrogen bonding generally leads to the formation of solute-solvent complexes, causing smoothing the fine structure. These bands are rapidly decreased in intensity until the near-infrared region is reached, without showing any additional absorptions.

As previously stated, the minimization of the damage to the body of the MWCNTs during their modification is very important for the maintenance of their original properties. To determine the thermal and oxidative stability of the modified MWCNTs in air, TGA was performed. The average weight loss for the various derivates $\left(\mathbf{1}-\mathrm{SbF}_{6}, \mathbf{1}-\mathrm{Cl}, \mathbf{1}\right.$-tartrate) was less than $10 \%$, even at $500{ }^{\circ} \mathrm{C}$, indicating high thermal stability (see supplementary material). This result stands in stark contrast to the case of MWCNTs modified via oxidative cutting method, where intensive decomposition of the MWCNTs begins at $<300{ }^{\circ} \mathrm{C} .{ }^{5}$ The TEM images showing the shapes of the nanotubes provided further support for the minimal change in their overall structure after modification. Moreover, the images clearly show that the soluble derivatives, 1-Cl and 1-tartrate, are individually dispersed, while the original MWCNTs are severely aggregated together.

\section{Conclusions}

A simple and novel technique for the preparation of airstable MWCNT-derivatives with positive charged sidewalls and a $\mathrm{SbF}_{6}$ counter anion was achieved by treating pristine MWCNTs with THF as an electrophile in the presence of fluoroantimonate ionic liquid [bmim] $\left[\mathrm{Sb}_{n} \mathrm{~F}_{5 \mathrm{n}+1}\right](\mathrm{n} \geq 2)$ as a Lewis acid activator. The derivatization took place very rapidly in a single pot under very mild reaction conditions. The ionic structure of the MWCNT-derivative enabled its tunable dissolution in various solvents through simple anion exchange. The protocol described in the present study is expected to open up new perspectives for positive chargedoping on the surface of other members of the fullerene family (single-walled nanotubes and graphenes) and their anion-directed dissolution.

Acknowledgments. This work was supported by grants from the National Research Foundation of Korea: 20090093829 (Priority Research Centers Program) and R312008-000-100069-0 (WCU program). Authors greatly thank the support of IBST of Dankook University.

Supplementary Data. Supplementary data associated with this article can be found, in the online version, at http:// journal.kcsnet.or.kr.

\section{References}

1. Iijima, S. Nature 1991, 354, 56.

2. Ajayan, P. M. Chem. Rev. 1999, 99, 1787.

3. Baughman, R. H.; Zakhidov, A. A.; de Heer, W. A. Science 2002, 297, 787.

4. Liu, J.; Rinzler, A. G.; Dai, H.; Hafner, J. H.; Bradley, R. K.; Boul, P. J. et al. Science 1998, 280, 1253.

5. Wang, Y.; Iqbal, Z.; Mitra, S. J. Am. Chem. Soc. 2006, 128, 95.

6. Kovtyukhova, N. I.; Mallouk, T. E.; Pan, L.; Dickey, E. C. J. Am. Chem. Soc. 2003, 125, 9761.

7. Chen, J.; Hamon, M. A.; Hu, H.; Chen, Y.; Rao, A. M.; Eklund, P. C. et al. Science 1998, 282, 95.

8. Yu, B.; Zhou, F.; Liu, G.; Liang, Y.; Huck, W. T. S.; Liu, W. Chem. Commun. 2006, 2356.

9. Fagnoni, M.; Profumo, A.; Merli, D.; Dondi, D.; Mustarelli, P.; Quartarone, E. Adv. Mater. 2009, 21, 1.

10. Pénicaud, A.; Poulin, P.; Derré, A.; Anglaret, E.; Petit, P. J. Am. Chem. Soc. 2005, 127, 8.

11. Ramesh, S.; Ericson, L. M.; Davis, V. A.; Saini, R. K.; Kittrell, C. et al. J. Phys. Chem. B 2004, 108, 8794.

12. Rao, A. M.; Eklund, P. C.; Bandow, S.; Thess, A.; Smalley, R. E. Nature 1997, 388, 257.

13. Liu, C. M.; Cao, H. B.; Li, Y. P.; Xu, H. B.; Zhang, Y. Carbon 2006, 44, 2919.

14. O’Connell, M. J.; Boul, P.; Ericson, L. M.; Huffman, C.; Wang, Y.; Haroz, E. et al. Chem. Phys. Lett. 2001, 342, 265.

15. Zheng, M.; Jagota, A.; Semke, E. D.; Diner, B. A.; Mclean, R. S.; Lustig, S. R. et al. Nature Mater. 2003, 2, 338.

16. Ishibashi, A.; Nakashima, N. Chem. Eur. J. 2006, 12, 7595.

17. Georgakilas, V.; Bourlinos, A.; Gournis, D.; Tsoufis, T.; Trapalis, C.; Mateo-Alonso, A. et al. J. Am. Chem. Soc. 2008, 130, 8733.

18. Han, S. W.; Oh, S. J.; Tan, L. S.; Baek, J. B. Carbon 2008, 46, 1841.

19. Bahr, J. L.; Yang, J.; Kosynkin, D. V. M.; Bronikowski, J.; Smalley, R. E.; Tour, J. M. J. Am. Chem. Soc. 2001, 123, 6536.

20. Mickelson, E. T.; Huffman, C. B.; Rinzler, A. G.; Smalley, R. E.; Hauge, R. H.; Margrave, J. L. Chem. Phys. Lett. 1998, 296, 188.

21. Aihara, J. J. Phys. Chem. 1994, 98, 9773.

22. Lee, H. H.; Shin, U. S.; Won, J. E.; Kim, H. W. Mater. Lett. 2011, $65,208$.

23. Lee, H. H.; Shin, U. S.; Jin, G. Z.; Kim, H. W. Bull. Korean Chem. Soc. 2011, 32, 157.

24. Shin, U. S.; Yoon, I. K.; Lee, G. S.; Jang, W. C.; Knowles, J. C.; Kim, H. W. J. Tissue Eng. 2011, in press.

25. Deshmukh, R. R.; Lee, J. W.; Shin, U. S.; Lee, J. Y.; Song, C. E. Angew. Chem. Int. Ed. 2008, 47, 8615.

26. Choi, D. S.; Kim, J. H.; Shin, U. S.; Deshmukh, R. R.; Song, C. E. Chem. Commun. 2007, 3482. 